\title{
J-V Decoupling: Independent Control Over Current and Potential in Electrocatalysis
}

\author{
Peter Agbo ${ }^{1,2,3 *}$
}

Chemical Sciences Division ${ }^{1}$, Joint Center for Artificial Photosynthesis ${ }^{2}$, Molecular Biophysics \& Integrated Bioimaging Division ${ }^{3}$, Lawrence Berkeley National Laboratory,

Berkeley CA 94720

*Corresponding author

pagbo@lbl.gov

\section{Supporting Information}

\section{Index}

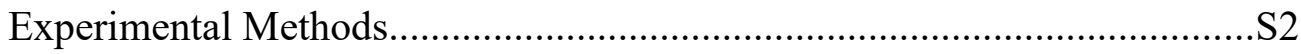

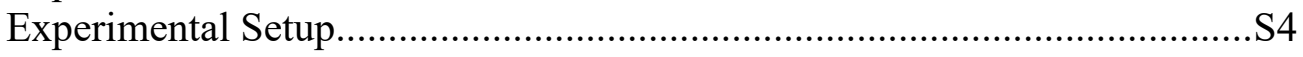

Electrochemical Cell Assembly Diagram..............................................S5

Analytical Derivation of Polarization Response .........................................S6

Voltage-Dependent Faradaic Efficiency Data, Device 1............................S8

Voltage-Dependent Faradaic Efficiency Data, Device 2 ...........................S10

Voltage-Dependent Faradaic Efficiency Data, Device 3..........................S12

Individual Product Faradaic Efficiencies vs JxV .....................................S14

$\mathrm{CO} / \mathrm{H}_{2}$ Faradaic Efficiency Ratios vs Voltage.......................................S15

PV Array Power Dependence................................................................S16

Electrochemical Impedance Spectra..........................................................S17

Table S1 - Same Voltage, Different Product Ratios..................................S18

Table S2 - Different Voltages, Same Product Ratios................................S19

Approximation of $\mathrm{CO}_{2}$ Surface Concentration......................................S22

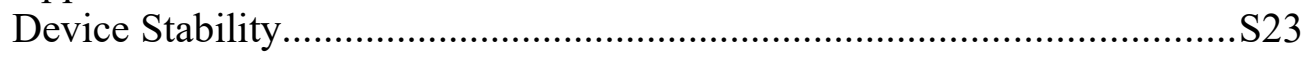




\section{Experimental Methods}

Radio Frequency Metal Sputtering

$\mathrm{Au}$ catalysts were deposited on Toray carbon paper (Fuel Cell Store) using an AJA radio frequency metal sputtering system. An Au target (99.99\% purity, Lawrence Berkeley National Laboratory) was used as the metal source. Membranes were loaded into an antechamber and pumped down to approximately $1 \mu$ Torr before loading into the main deposition chamber. The sample plate was rotated to ensure even deposition thickness across the substrates. Chamber pressure was adjusted to 3 mTorr Argon and the Au target tuned to 150 watts ( 0 watt reflected power); typical target voltage was $160 \mathrm{~V}$. A deposition rate of $(3.0 \AA / \mathrm{s})$ was measured using an internal quartz crystal microbalance. Following target tuning the shutter target was opened, exposing the sample to the plasma for 5.5 minutes in order to establish a $100 \mathrm{~nm}$ of $\mathrm{Au}$ on the Toray carbon papers. Afterwards, the shutter was closed, and the samples were removed from the chamber.

The resulting thickness of deposited Ir was $100 \mathrm{~nm}$, controlled by monitoring the sputter deposition rate with a quartz crystal. The Ir (99.9\%) target was fabricated in-house at Lawrence Berkeley National Laboratory. A $100 \mathrm{~nm}$ layer of Ir catalyst was deposited on the carbon papers by RF sputtering in a 3 mTorr atmosphere of Ar at $150 \mathrm{~W}$.

\section{Cell Fabrication and Assembly}

$50 \mathrm{~mm}$ x $50 \mathrm{~mm}$ cell endplates were fabricated from polymethylmethacrylate (PMMA, McMaster-Carr Supply Company, Santa Fe Springs, CA) in house at Berkeley Lab. The flow channels for supplying the anode and cathode feeds were attached with a two-component epoxy (EPO-TEK® 302-3M) to each endplate. Torx screws were then used compress the cell components following their vertical stacking and alignment in the following order (Figure S2):

1) Cathode endplate with flow ports

2) $50 \mathrm{~mm} \times 50 \mathrm{~mm}$ orange silicone gasket ( $1 \mathrm{~mm}$ thick) with $2 \mathrm{~cm} \times 1.1 \mathrm{~cm}$ substrate channel

3) Ta foil current collector with $2 \mathrm{~cm} \times 1.1 \mathrm{~cm}$ substrate channel

4) $\mathrm{Au} /$ Carbon cathode $2 \mathrm{~cm} \times 1.25 \mathrm{~cm}$ (Au layer face up)

5) Selemion AMV membrane

6) $\mathrm{Ir} /$ Carbon anode, $2 \mathrm{~cm} \times 1.25 \mathrm{~cm}$ (Ir layer face down)

7) Ta foil current collector with $2 \mathrm{~cm} \times 1.1 \mathrm{~cm}$ substrate channel

8) $50 \mathrm{~mm} \times 50 \mathrm{~mm}$ silicone gasket ( $3 \mathrm{~mm}$ thick), with $2 \mathrm{~cm} \times 1.1 \mathrm{~cm}$ substrate channel

9) Black gasket (Kalrez ${ }^{\circledR}$ perfluoroelastomer, K\# 5021, Compound 6375, $0.5 \mathrm{~mm}$ thick), $1.6 \mathrm{~cm}$ x $2.75 \mathrm{~cm} ; 2 \mathrm{~cm}$ x $1.1 \mathrm{~cm}$ substrate channel.

10) Anode endplate with flow ports

The Ta current collectors were fabricated using electrical discharge machining (EDM) or laser cutting $100 \mu \mathrm{m}$ thick tantalum foil, creating $0.9 \mathrm{~mm}$ wide channels, $100 \mu \mathrm{m}$ wide lands and channel lengths of $17.3 \mathrm{~mm}$. Selemion AMV was used as the ionomer in these experiments. Prior to testing, membranes were stored in $0.5 \mathrm{M} \mathrm{KOH}$ solution.

\section{Dark- and Photo-voltammetry}

Electrochemical measurements were performed using a Gamry Reference 600+ potentiostat. The 100 $\mathrm{nm} \mathrm{Ir} /$ carbon substrate served as the anode catalyst, acting on an anolyte consisting of $1 \mathrm{M}$ potassium bicarbonate prepped in Millipore water, which was pumped through the anode volume at a rate of 10 $\mathrm{ml} \mathrm{min} \mathrm{m}^{-1}$ via peristalsis. Cells were allowed to equilibrate for at least an hour, to facilitate membrane hydration before the start of device testing. During this period, the cell cathode compartment was 
flushed with $\mathrm{CO}_{2}$ (Airgas) at a rate of $5 \mathrm{sccm}$. Gas flow rates were controlled using flow meters (0.5-10 sccm resolution) purchased from Alicat Scientific. Following the cell equilibration period, cyclic voltammetry $(\mathrm{CV})$ was performed by recursive polarizations of $0 \rightarrow-3 \mathrm{~V} \rightarrow 0 \mathrm{~V}$ at a scan rate of 100 $\mathrm{mV} \mathrm{s}^{-1}$, until the scans converged at a stable value. All applied potentials are referenced vs a full-cell potential, with the anode termination serving as a pseudoreference and the Au cathode as the working electrode. Afterwards a linear sweep voltammogram (LSV) was collected by scanning from 0 to $-3 \mathrm{~V}$ at a $10 \mathrm{mV} \mathrm{s}^{-1}$ scan rate. At the end of chronoamperometric trials, LSVs were collected at $10 \mathrm{mV} \mathrm{s}^{-1}$ to determine any changes in the cell's electrochemical response resulting from extended device operation.

For photo-driven experiments, a $150 \mathrm{~W}$ xenon lamp (Newport) was used to illuminate a photovoltaic array comprised of two independent PV modules $\left(26.62 \mathrm{~cm}^{2} /\right.$ module, Spectrolabs) connected in series. The measured $\mathrm{V}_{\mathrm{oc}}$ for this series-connected PV array was $4.65 \mathrm{~V}$ with a shortcircuit current of $22 \mathrm{~mA}$ under maximum illumination from the xenon lamp. A peak lamp power of 695 $\mathrm{mW}$ at $500 \mathrm{~nm}$ was measured using a power meter (Newport) after subtracting influences from ambient light and zeroing the instrument baseline, corresponding to a $27 \mathrm{~mW} \mathrm{~cm}^{-2}$ illumination intensity at the PV surface $\left(25.5 \mathrm{~cm}^{2}\right.$ spot size). The optical path proceeding from lamp to PV was as follows:
1) Lamp
2) Convex (focusing) optic
3) Iris
4) Rotary, continuously-variable neutral density filter (Thorlabs)
5) Power meter post (lamp measurement only)
6) PV array

Adjustments to incident lamp intensity were made by mounting the power meter in the beam path and adjusting the rotary filter to desired values of lamp intensity at $500 \mathrm{~nm}$ and current, as registered by the power meter and potentiostat, respectively. Once set, the power meter was removed and voltammetry was run by biasing the PV array connected to the electrochemical cell (Figure S1) from 4.65 to $0 \mathrm{~V}$; potentiostatic experiments were run by setting a desired voltage set point at the light intensity of interest.

\section{Electrochemical Impedance Spectroscopy}

IR-corrections to polarization data were performed through collection of the electrochemical device impedance at a $-3.0 \mathrm{~V}$ applied cell voltage (dark) with a $10 \mathrm{mV}$ perturbation amplitude, over a frequency range spanning $0.2 \mathrm{~Hz}-1 \mathrm{MHz}$.

\section{Gas Chromatography (GC)}

Measurement of gas-phase, $\mathrm{CO}_{2}$ reduction products were determined using an SRI 8610 Gas Chromatograph (MG-5 device configuration). TCD and FID detectors were calibrated using standardized tanks for hydrogen and carbon monoxide at various concentrations acquired from Airgas. Argon (Airgas) was used as a carrier fluid $\left(30 \mathrm{ml} \mathrm{min}^{-1}\right.$ flow rate) for the GC columns.

\section{Chemicals \& Solutions}

Potassium bicarbonate purchased from Sigma-Aldrich were used to prepare $1 \mathrm{M} \mathrm{KHCO}_{3}$ solutions made in millipore water for use as the electrochemical cell anolyte.

Data Analysis

Data workup was conducted using custom scripts written in the python programming environment. 


\section{Experimental Setup and Electrical Connectivity}

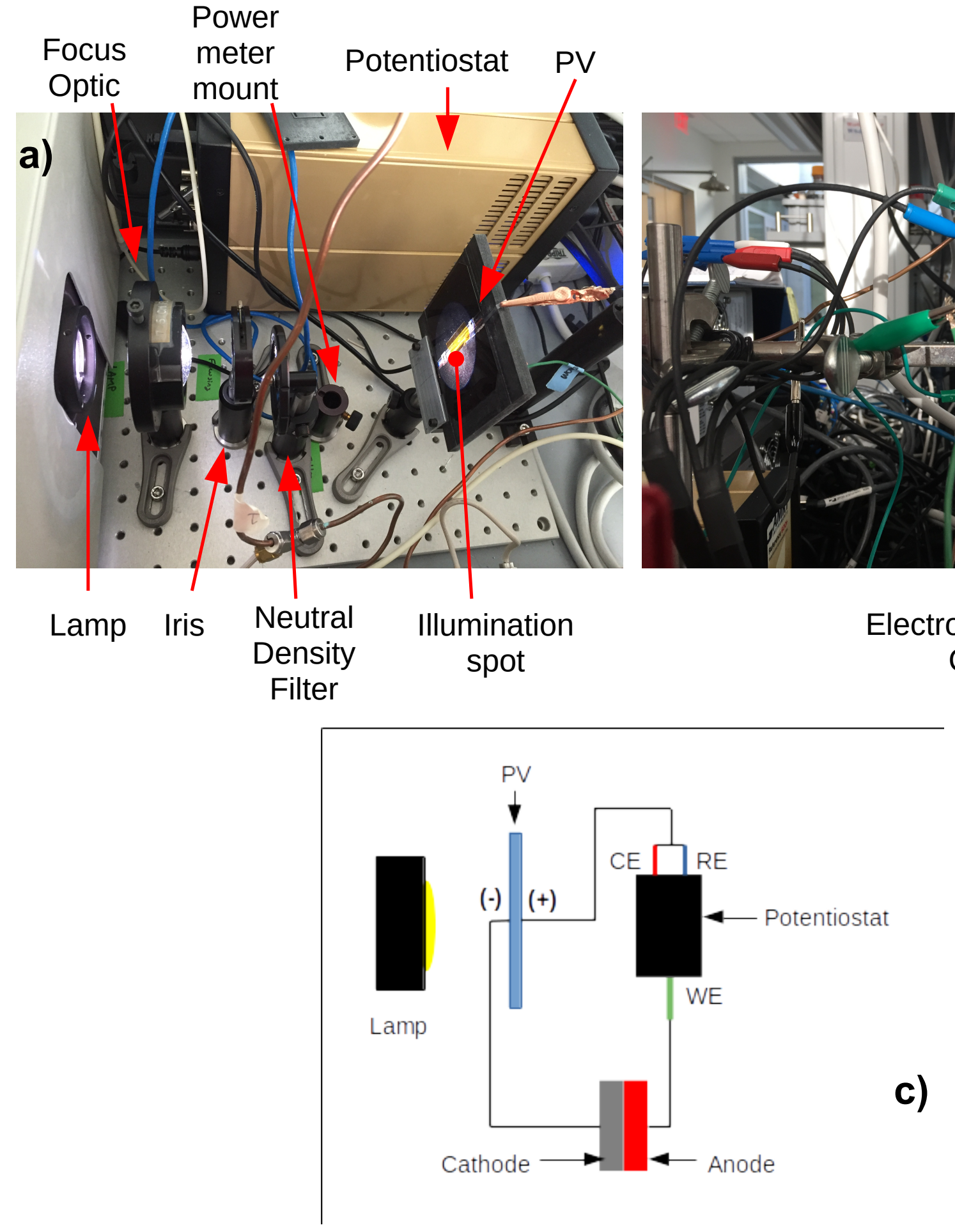

Figure S1

a) optical setup. b) electrochemical cell used for testing c) electrical connectivity diagram 


\section{Electrochemical Cell Assembly Diagram}

An exploded profile view of the electrochemical compression cell used for experiments in this study.

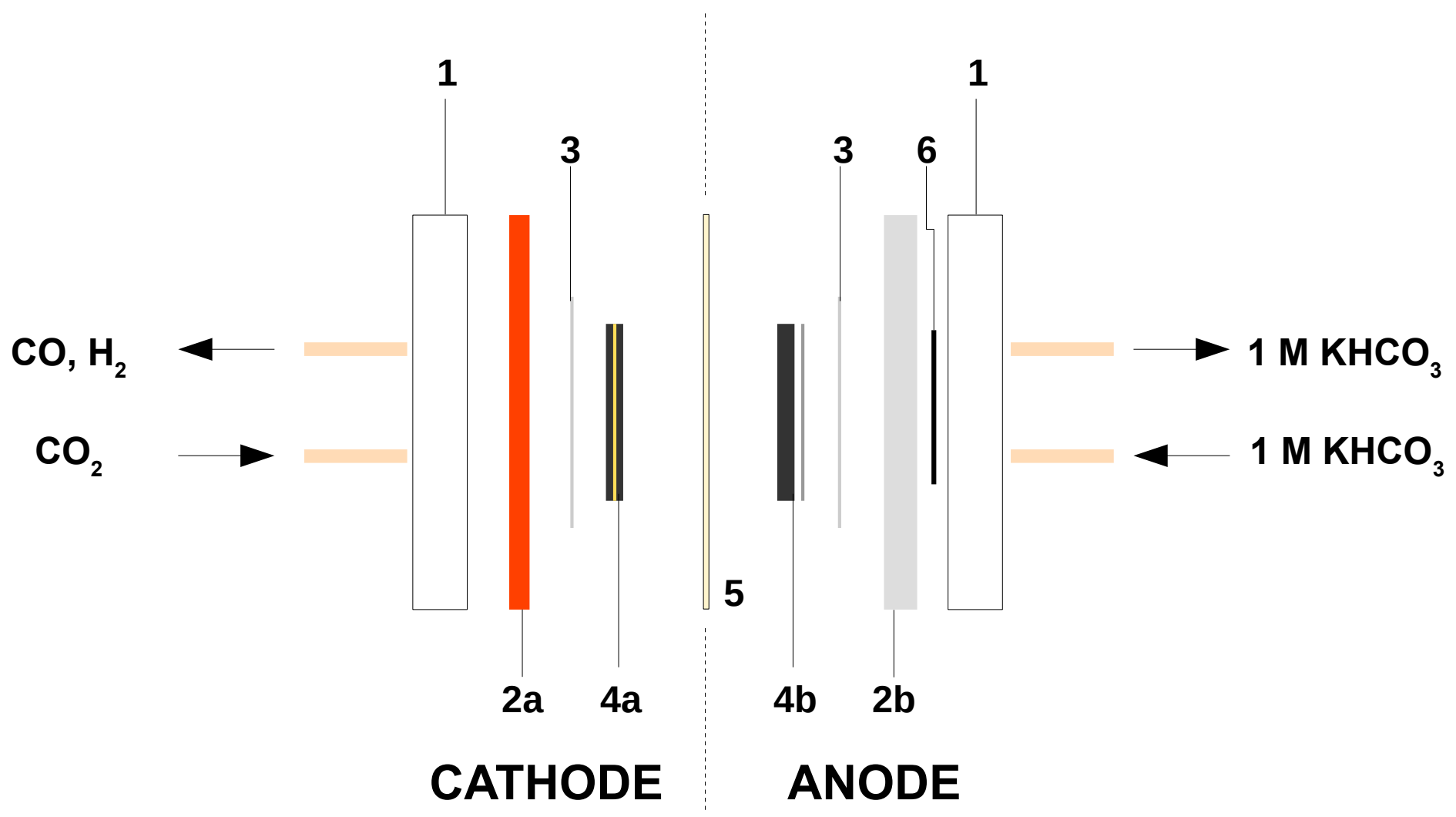

Figure S2

1. $50 \times 50 \mathrm{~mm}$ polyacrylamide endplate

2a. $1 \mathrm{~mm}$ silicone gasket

2b. $3 \mathrm{~mm}$ silicone gasket

3. Ta foil current collector

4a. $100 \mathrm{~nm}$ Au catalyst on Toray Carbon paper $\left(2.5 \mathrm{~cm}^{2}\right)$

4b. $100 \mathrm{~nm}$ Ir catalyst on Toray Carbon paper $\left(2.5 \mathrm{~cm}^{2}\right)$

5. Selemion AMV anion exchange membrane

6. $0.5 \mathrm{~mm}$ silicone gasket 


\section{Analytical Derivation of Polarization Response}

Light-Coupled Polarization

Assume an electrochemical reaction occurring at an electrode-substrate interface according to the following mechanism:

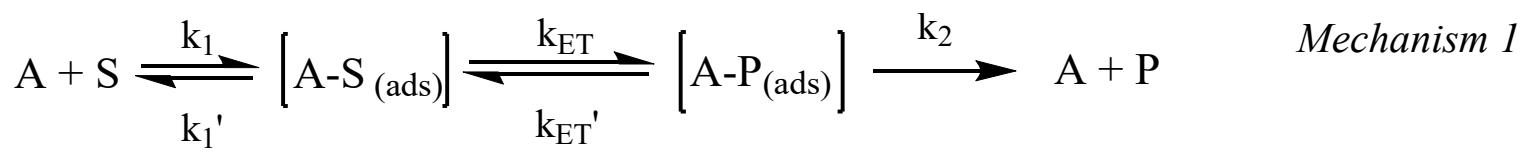

In this mechanism, $A_{T}$ is the total active site density, $\mathrm{S}$ is the substrate concentration, $\mathrm{A}-\mathrm{S}_{(\mathrm{ads})}$ is the density of active sites with adsorbed substrate $\left(\mathrm{CO}_{2}, \mathrm{H}^{+}\right)$, A-P $\mathrm{P}_{(\mathrm{ads})}$ is the density of active sites with adsorbed product (i.e, $\mathrm{CO}_{(\mathrm{ads})}, \mathrm{H}_{2(\mathrm{ads})}$ ). $\mathrm{P}$ gives the concentration of free product.

For $\mathrm{Au}$-mediated $\mathrm{CO}_{2}$ reduction, take electrochemical reduction of the adsorbed product species to be the rate-determining process in the catalytic cycle. This is consistent with reports that $\mathrm{CO}_{2}$ reduction over polycrystalline $\mathrm{Au}$ is rate-limited by ET to $\mathrm{CO}_{2}$ adsorbates ${ }^{28}$, and assumes that substrate interconversion between substrate-free and electrode-adsorbed states are characterized by rapid equilibria. Processes such as substrate protonation and conformational changes are not explicit in this model, allowing for a more generalized treatment of PEC polarization behavior. With ET to the substrate as our rate-determining step, we start from the rate law:

$$
r=k_{E T}\left[A-S_{(a d s)}\right]-k_{E T}^{\prime}\left[A-P_{(a d s)}\right] .
$$

The density of intermediate active sites states during catalytic turnover, $[\mathrm{A}],\left[\mathrm{A}-\mathrm{S}_{(\mathrm{ads})}\right]$ and $\left[\mathrm{A}-\mathrm{P}_{(\mathrm{ads})}\right]$ are hard to quantify and should be expressed in terms of the total active site density ([A] $]_{\mathrm{T}}$, which is known. To do this, an analytical solution to the following homogeneous system of differential equations is found:

$$
\begin{aligned}
& \text { (A) } \frac{d[A]}{d t}=-k_{1}[A][S]+k_{1}^{\prime}\left[A-S_{(a d s)}\right]+k_{2}\left[A-P_{(a d s)}\right]=0 \\
& \text { (B) } \frac{d\left[A-S_{(a d s)}\right]}{d t}=k_{1}[A][S]-k^{\prime}{ }_{1}\left[A-S_{(a d s)}\right]-k_{E T}\left[A-S_{(a d s)}\right]+k_{E T}^{\prime}\left[A-P_{(a d s)}\right]=0 \\
& \text { (C) } \frac{d\left[A-P_{(a d s)}\right]}{d t}=k_{E T}\left[A-S_{(a d s)}\right]-k_{E T}^{\prime}\left[A-P_{(a d s)}\right]-k_{2}\left[A-P_{(a d s)}\right]=0
\end{aligned}
$$

Charge conservation also requires that:

$$
\text { (D) } \frac{d q}{d t}=k_{E T}\left[A-S_{(a d s)}\right]-k_{E T}^{\prime}\left[A-P_{(a d s)}\right]+k_{P V}=0 \text {, }
$$

for a PV-driven system. Solving for the term $\left[\mathrm{A}-\mathrm{P}_{(\mathrm{ads})}\right]$ yields:

$$
\left[A-S_{(a d s)}\right]=\frac{k_{E T}^{\prime}\left[A-P_{(a d s)}\right]-k_{P V}}{k_{E T}^{\prime}} \text {. }
$$


Note: $\mathrm{k}_{\mathrm{PV}}$ is the ensemble current density expressed as a rate $\left(\mathrm{s}^{-1} \mathrm{~cm}^{-2}\right) ; \mathrm{k}_{\mathrm{ET}}$ and $\mathrm{k}_{\mathrm{ET}}$ are unimolecular electron transfer rate constants normalized on a per-active site basis, with units of $\mathrm{s}^{-1}$.

The sum of all intermediate states of the catalyst active sites equal to the initial active site density, $[\mathrm{A}]_{\mathrm{T}}$ :

$$
\begin{aligned}
& {[A]_{T}=[A]+\left[A-S_{(a d s)}\right]+\left[A-P_{(a d s)}\right]} \\
& {[A]_{T}=\left[A-S_{(a d s)}\right]\left(\frac{1}{k_{1}[S]}\left(k^{\prime}{ }_{1}+\frac{k_{2} k_{E T}}{k_{E T}^{\prime}+k_{2}}+1+\frac{k_{E T}}{k^{\prime}{ }_{E T}}\right)\right)-\frac{k_{P V}}{k_{E T}^{\prime}} ;} \\
& \frac{k_{E T}\left([A]_{T}+\frac{k_{P V}}{k_{E T}^{\prime}}\right)}{\frac{1}{k_{1}[S]}\left(k_{1}^{\prime}+\frac{k_{2} k_{E T}}{k_{E T}^{\prime}+k_{2}}\right)+1+\frac{k_{E T}}{k_{E T}^{\prime}}}=\left[A-S_{(a d s)}\right] ;\left[A-P_{(a d s)}\right]=\frac{k_{E T}\left[A-S_{(a d s)}\right]}{k_{E T}^{\prime}+k_{2}}
\end{aligned}
$$

Substituting the expression for $\left[\mathrm{A}-\mathrm{S}_{(\mathrm{ads})}\right]$ and $\left[\mathrm{A}-\mathrm{P}_{(\mathrm{ads})}\right]$ into the definition for $\mathrm{r}$ yields the rate equation in terms of the readily measured quantities $[\mathrm{A}]_{\mathrm{T}}$ :

$$
r(\phi, V)=k_{E T}^{\prime}\left(1-\frac{k_{E T}^{\prime}}{k_{E T}^{\prime}+k_{2}}\right) \frac{[A]_{T}+\frac{k_{P V}(\phi, V) f}{k_{E T}^{\prime}}}{\frac{1}{k_{1}[S]}\left(k^{\prime}{ }_{1}+\frac{k_{2} k_{E T}}{k_{2}+k^{\prime}{ }_{E T}}\right)+1+\frac{k_{E T}}{k^{\prime}}} \quad ; f=\frac{[A]_{T}\left(k_{E T}+k_{E T}^{\prime}\right)}{[A]_{T}\left(k_{E T}+k_{E T}^{\prime}\right)+k_{P V}} ;
$$

$f$ is a unitless, empirical factor that allows the function to converge to zero in the limit $[\mathrm{A}]_{\mathrm{T}} \rightarrow 0$. Multiplication of $r$ by the factor $n_{e} F / N_{A}$, yields the light-dependent current density, eq. $2 \mathrm{a}$.

\section{Dark polarization}

Scheme 1 remains relevant to electrochemical polarization under dark conditions. From equation (C):

$$
\left[A-P_{(a d s)}\right]=\left(\frac{k_{E T}}{k_{E T}^{\prime}+K_{2}}\right)\left[A-S_{(a d s)}\right]
$$

as for the light-coupled case, we first find a solution for $[\mathrm{A}]_{\mathrm{T}}$ in the dark system by applying mass conservation for the active site density:

$$
\begin{aligned}
& {[A]_{T}=[A]+\left[A-S_{(a d s)}\right]+\left[A-P_{(a d s)}\right]} \\
& {[A]_{T}=\left(\frac{k_{E T}}{k^{\prime}{ }_{E T}+k_{2}}\right)\left[A-S_{(a d s)}\right]+\left[A-S_{(a d s)}\right]\left(1+\frac{1}{k_{1}[S]}\left(k^{\prime}{ }_{1}+\frac{k_{2} k_{E T}}{k^{\prime}{ }_{E T}+k_{2}}\right)\right) ;}
\end{aligned}
$$

substituting the resulting solution for $\left[\mathrm{A}-\mathrm{S}_{(\mathrm{ads})}\right]$ into the rate law for $\mathrm{r}$ yields:

$$
r(V)=\frac{k_{E T}[A]_{T}}{\left(\frac{k_{E T}}{k_{E T}^{\prime}+k_{2}}\right)+\left(1+\frac{1}{k_{1}[S]}\left(k^{\prime}{ }_{1}+\frac{k_{2} k_{E T}}{k_{2}+k^{\prime}{ }_{E T}}\right)\right)}\left(1-\frac{k_{E T}^{\prime}}{k_{E T}^{\prime}+k_{2}}\right) ; \mathrm{J}_{\mathrm{dark}}=\mathrm{n}_{\mathrm{e}} \mathrm{Fr} / \mathrm{N}_{\mathrm{A}} .
$$


Voltage-Dependent Faradaic Efficiency Data - Devices 1,2\&3

Device 1

Figure S3

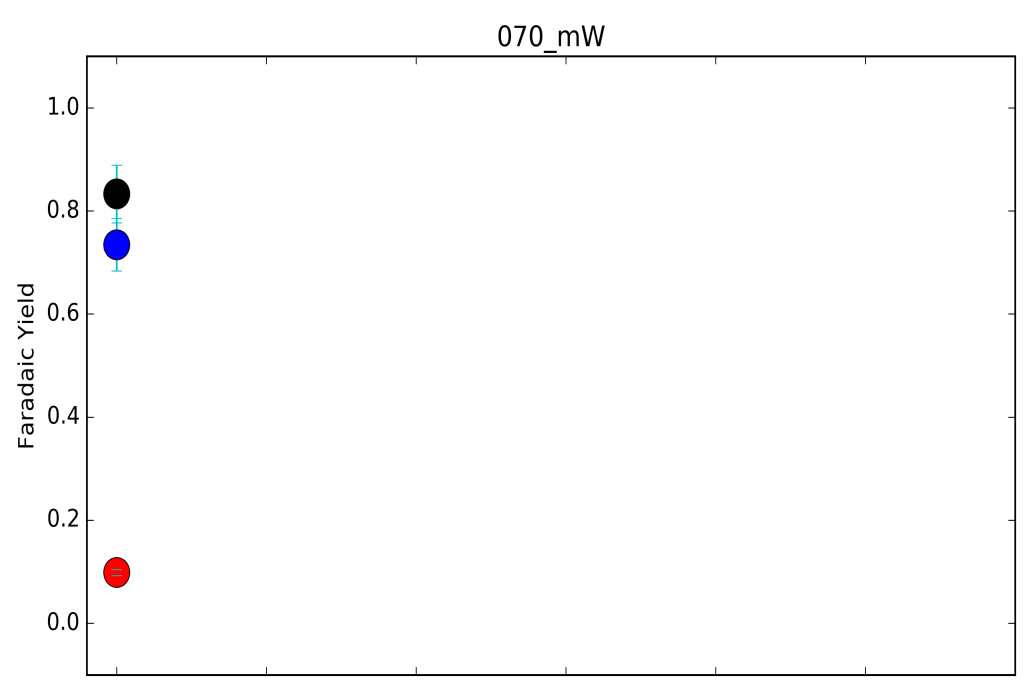

Total F.E.

CO F.E.

$H_{2}$ F.E.
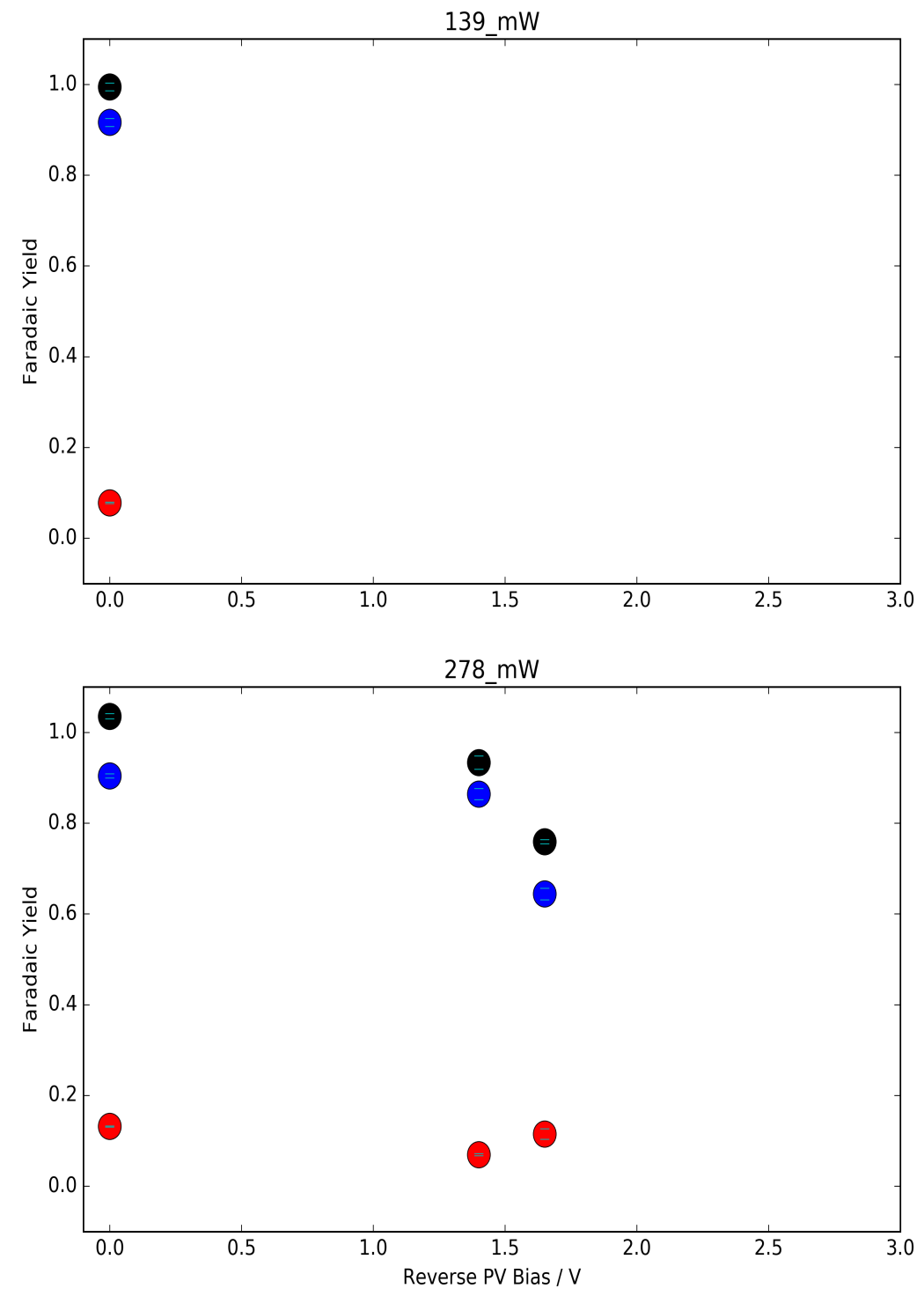
Device 1

Figure S4
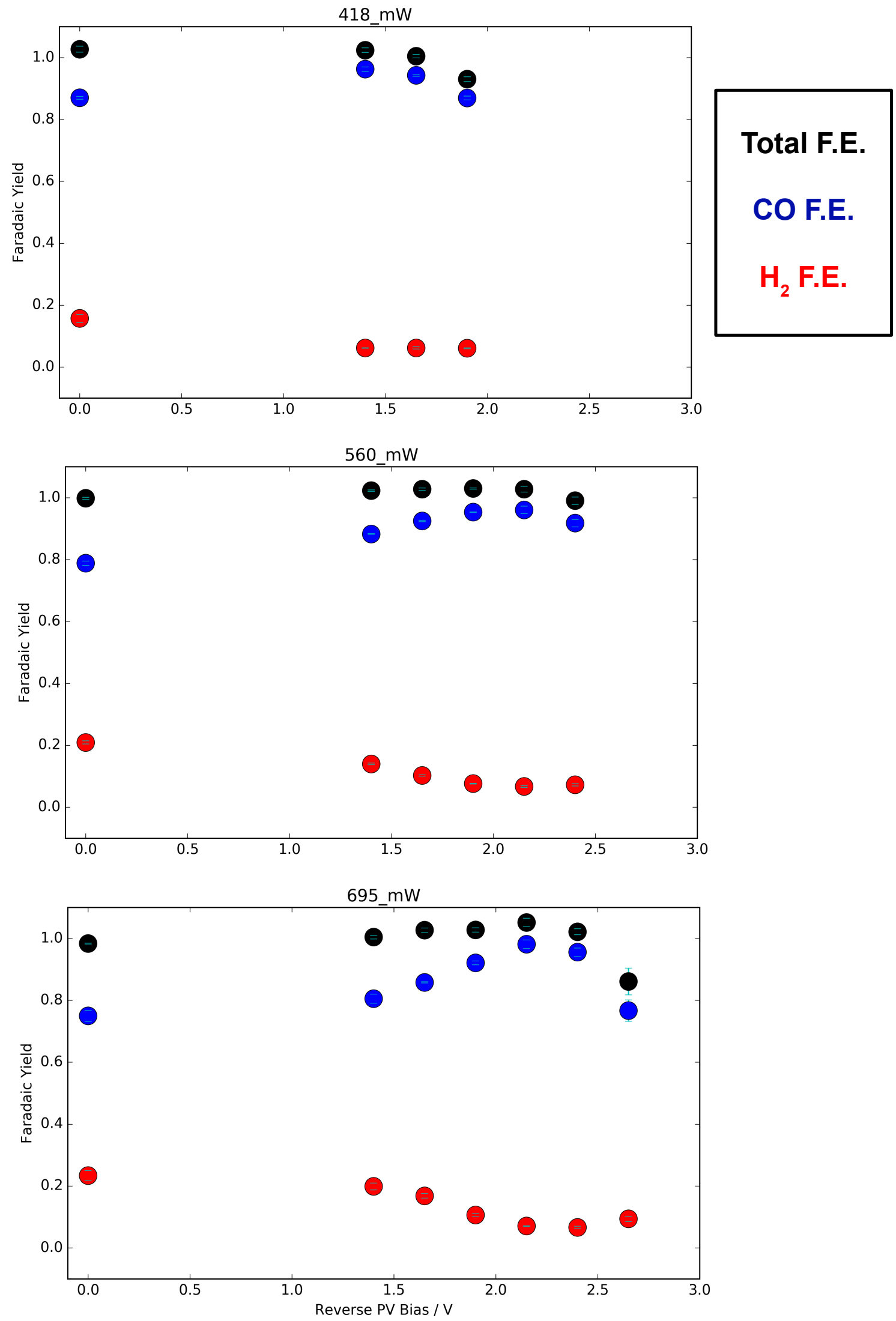
Device 2

Figure S5
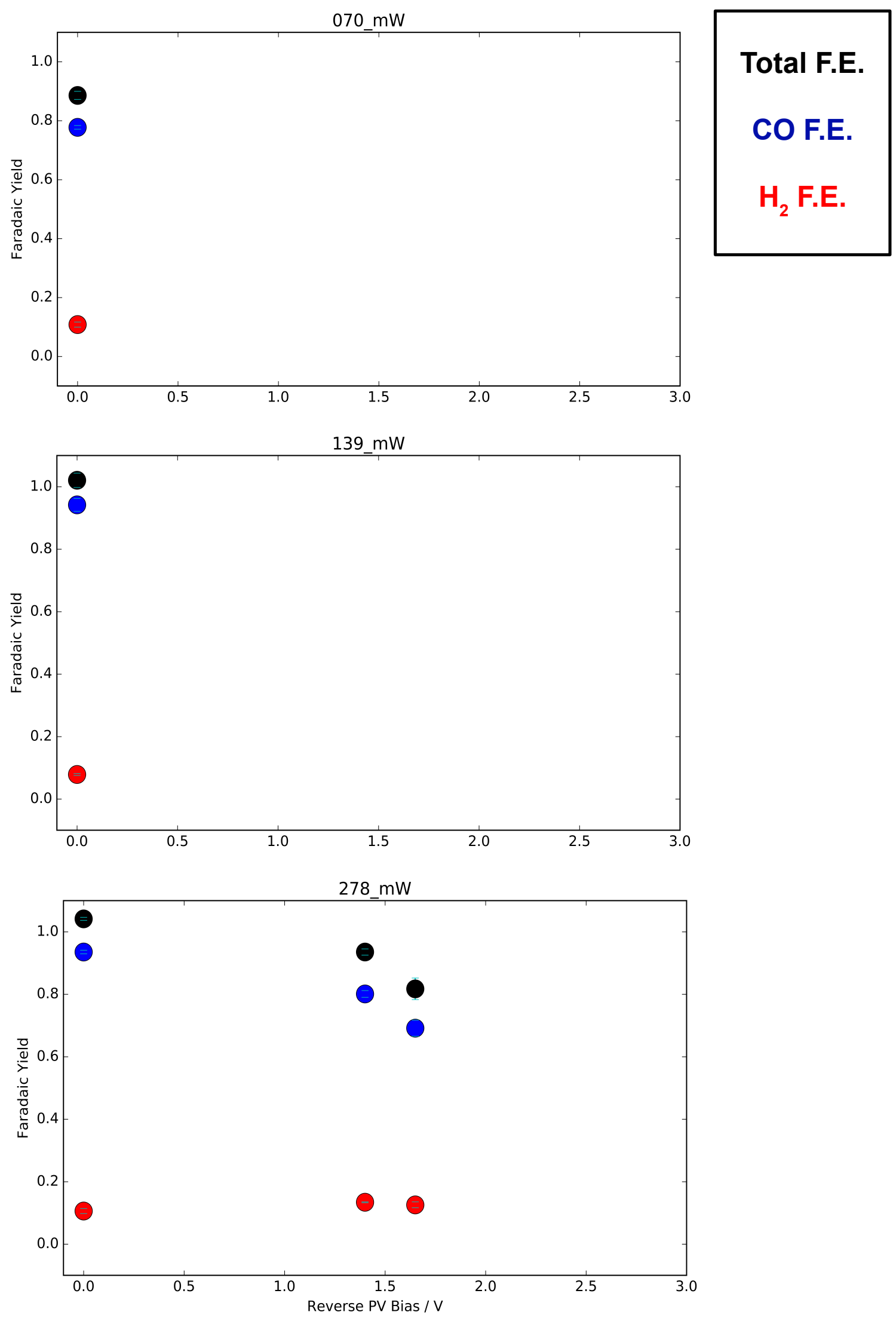

S10 
Device 2

Figure S6

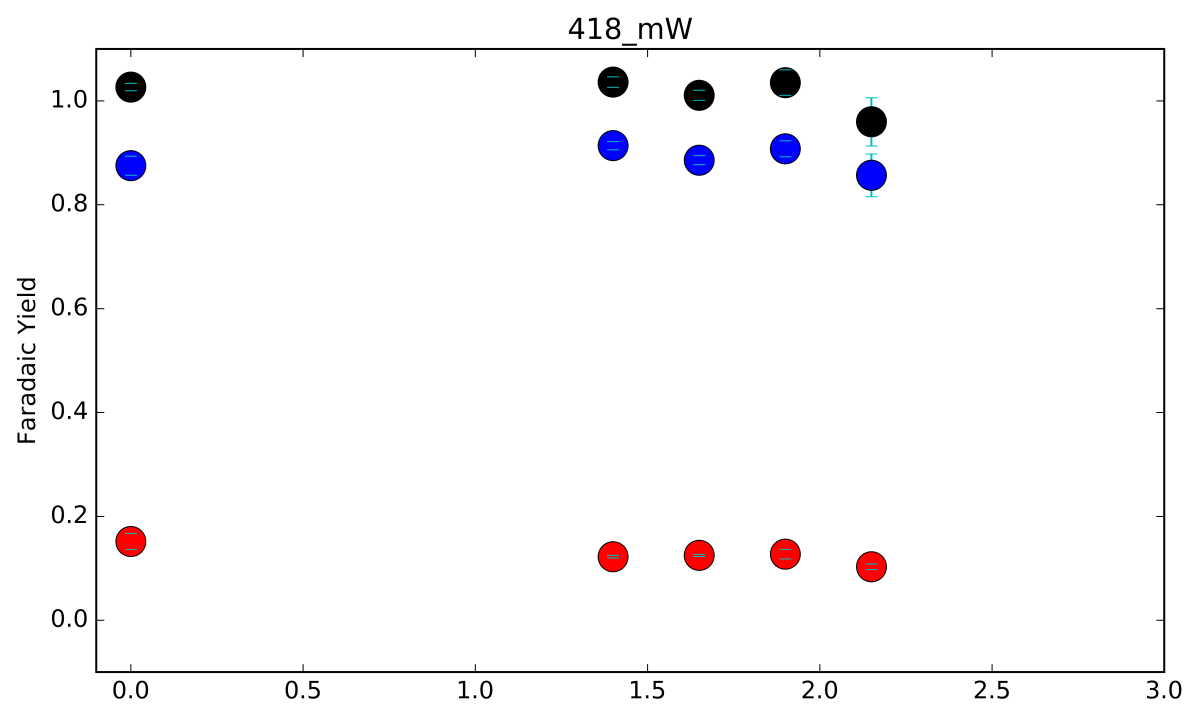

Total F.E. CO F.E.

$H_{2}$ F.E.
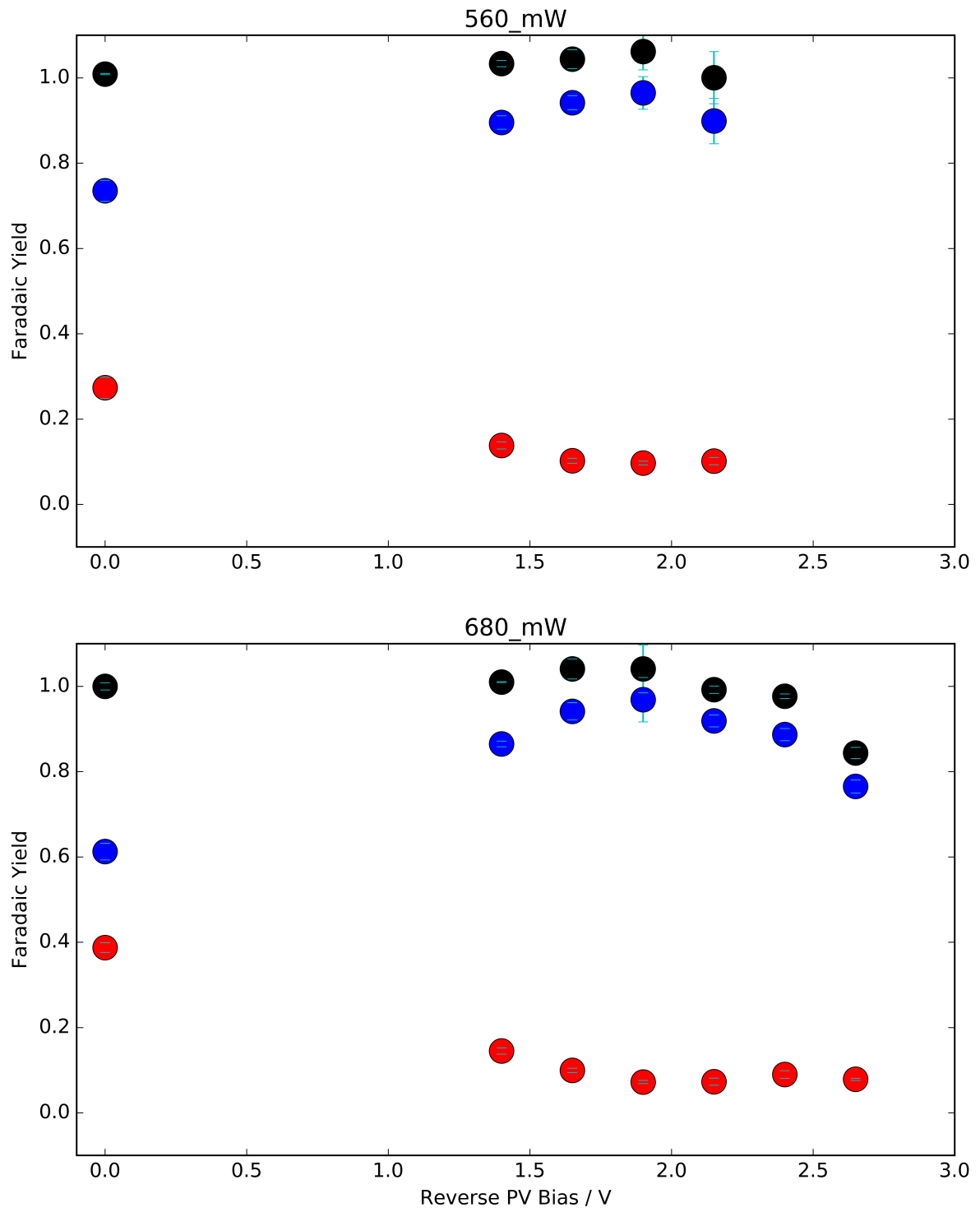
Device 3

Figure S7
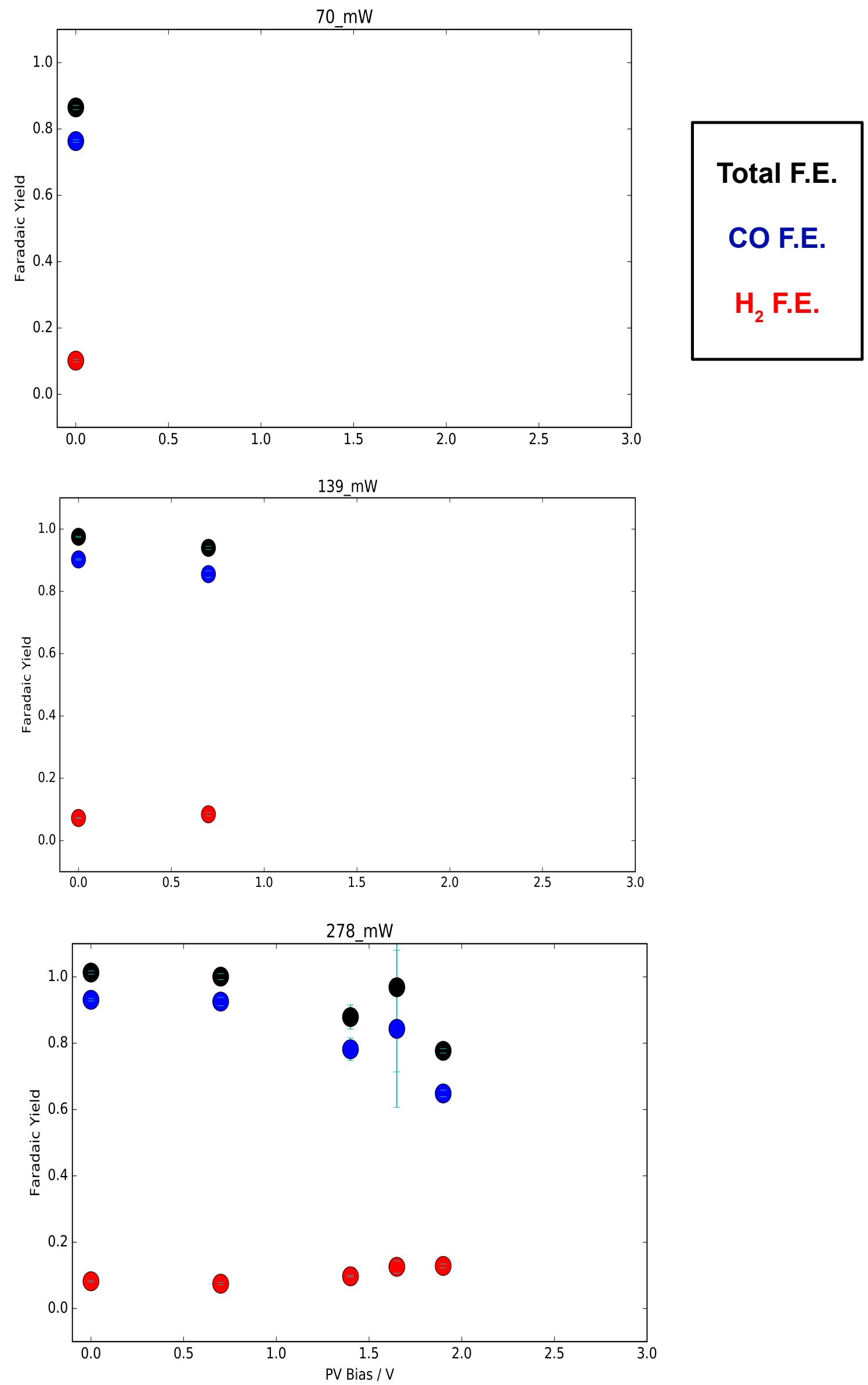

S12 
Device 3

Figure S8
$418 \mathrm{~mW}-2$

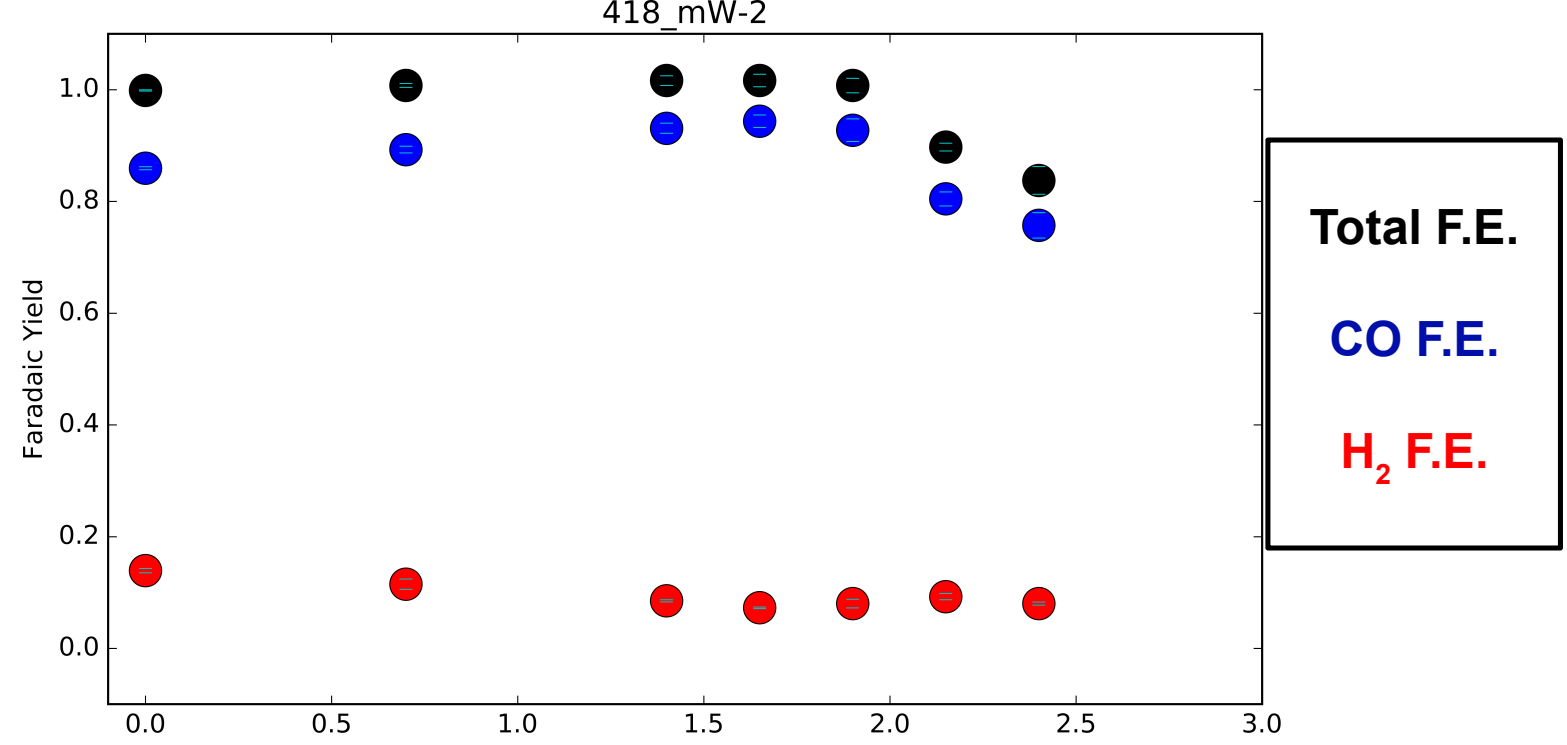

560_mW

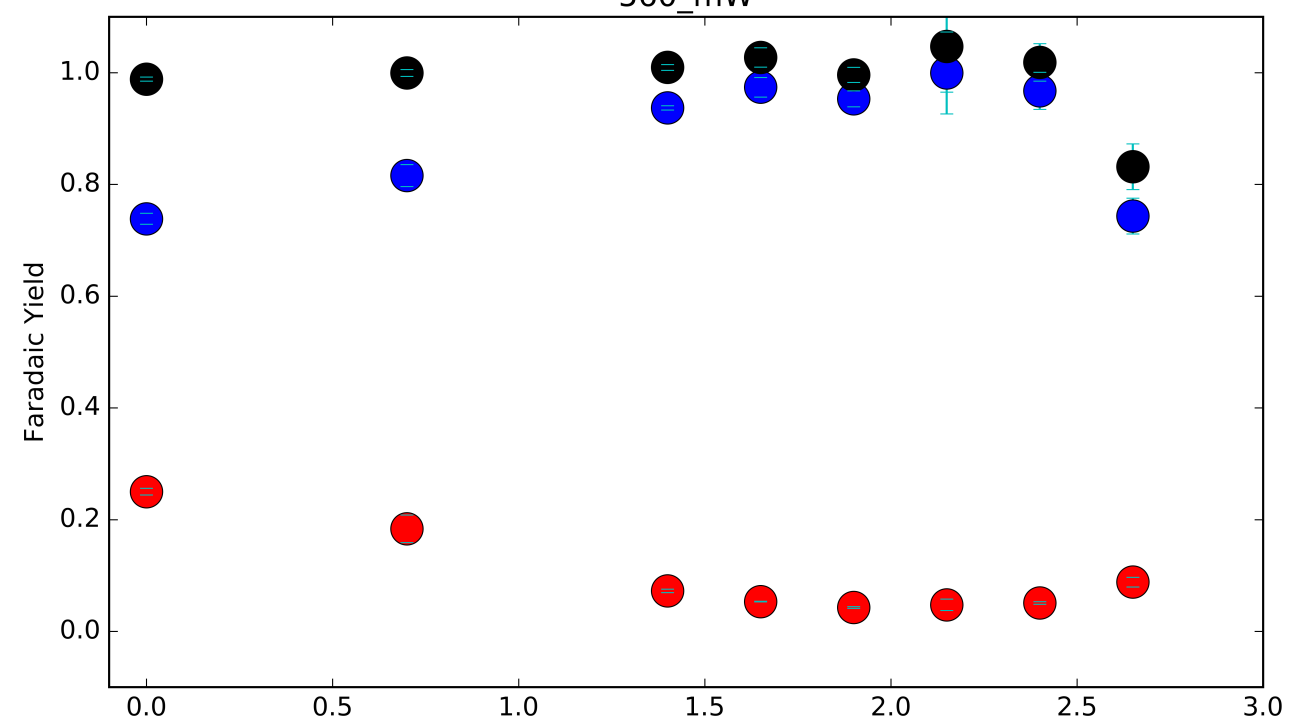

680 mW-2

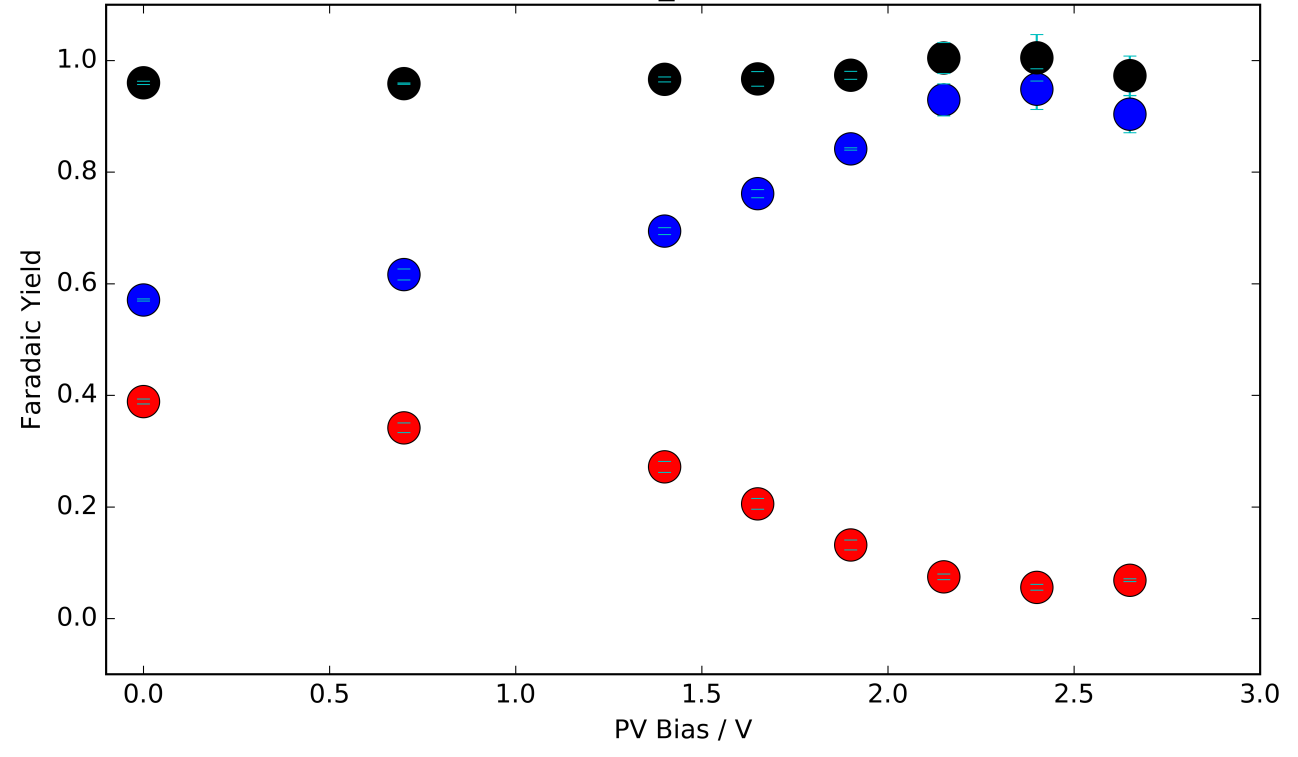

S13 
Individual Product Faradaic Efficiencies vs Device Electrical Power, JxV - Figure S9
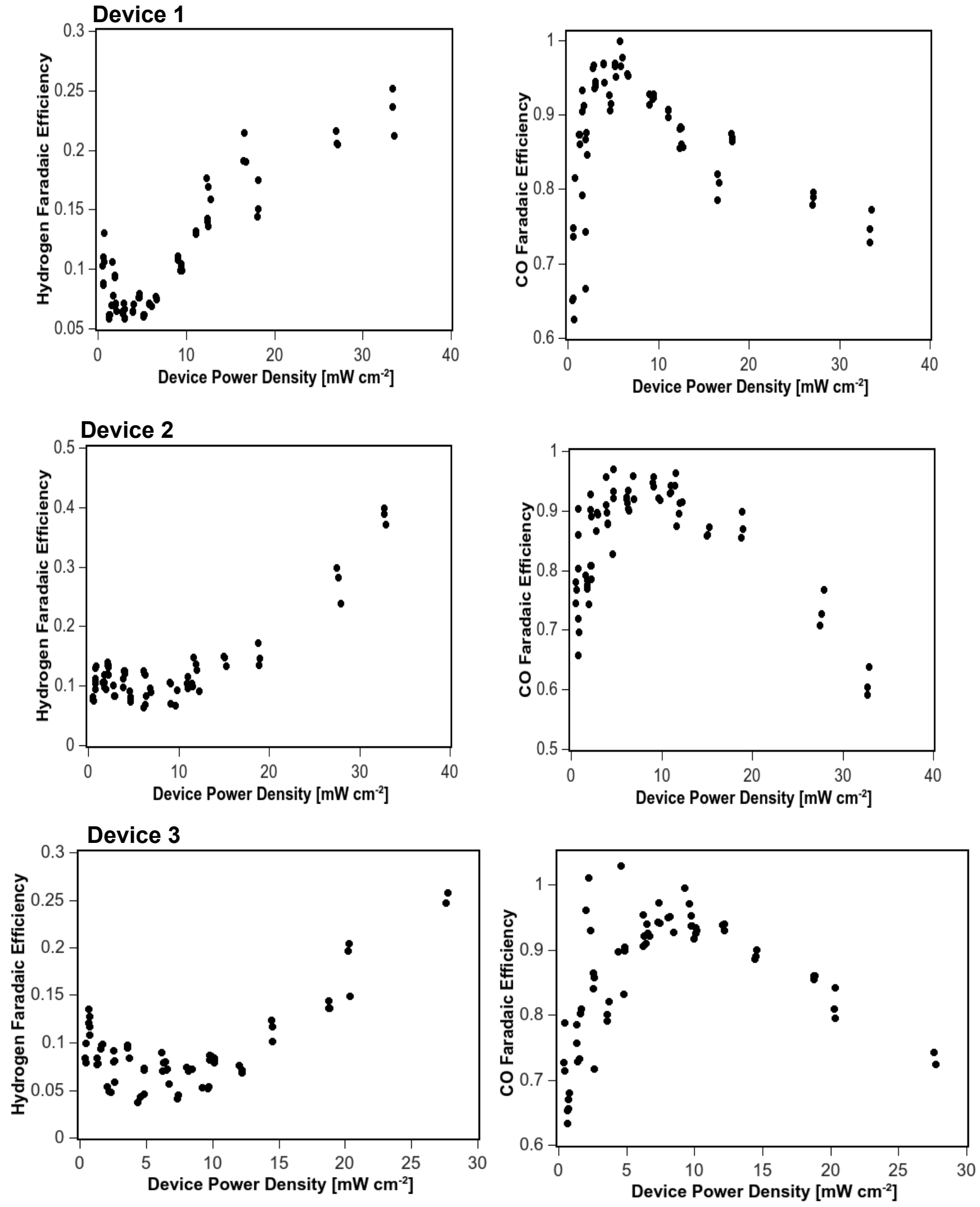

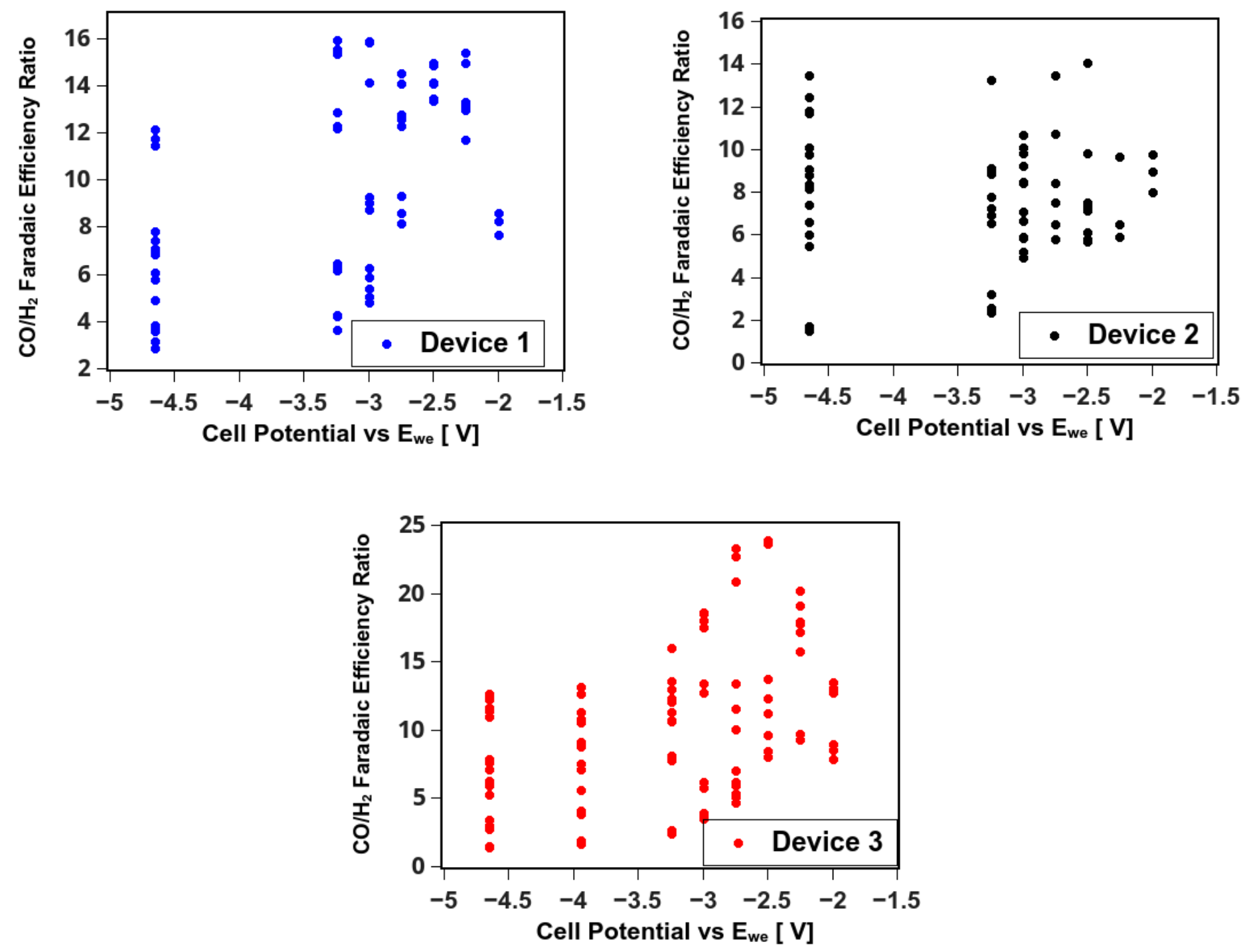

Figure S9 - CO/H $/ \mathrm{H}_{2}$ Faradaic Efficiency Ratio vs Voltage

Unlike measurements of $\mathrm{CO} / \mathrm{H}_{2}$ Faradaic yields vs the device electrical power $(\mathrm{JxV})$, inspection of the voltage-dependence of the $\mathrm{CO} / \mathrm{H}_{2}$ ratio displays no correlation. 


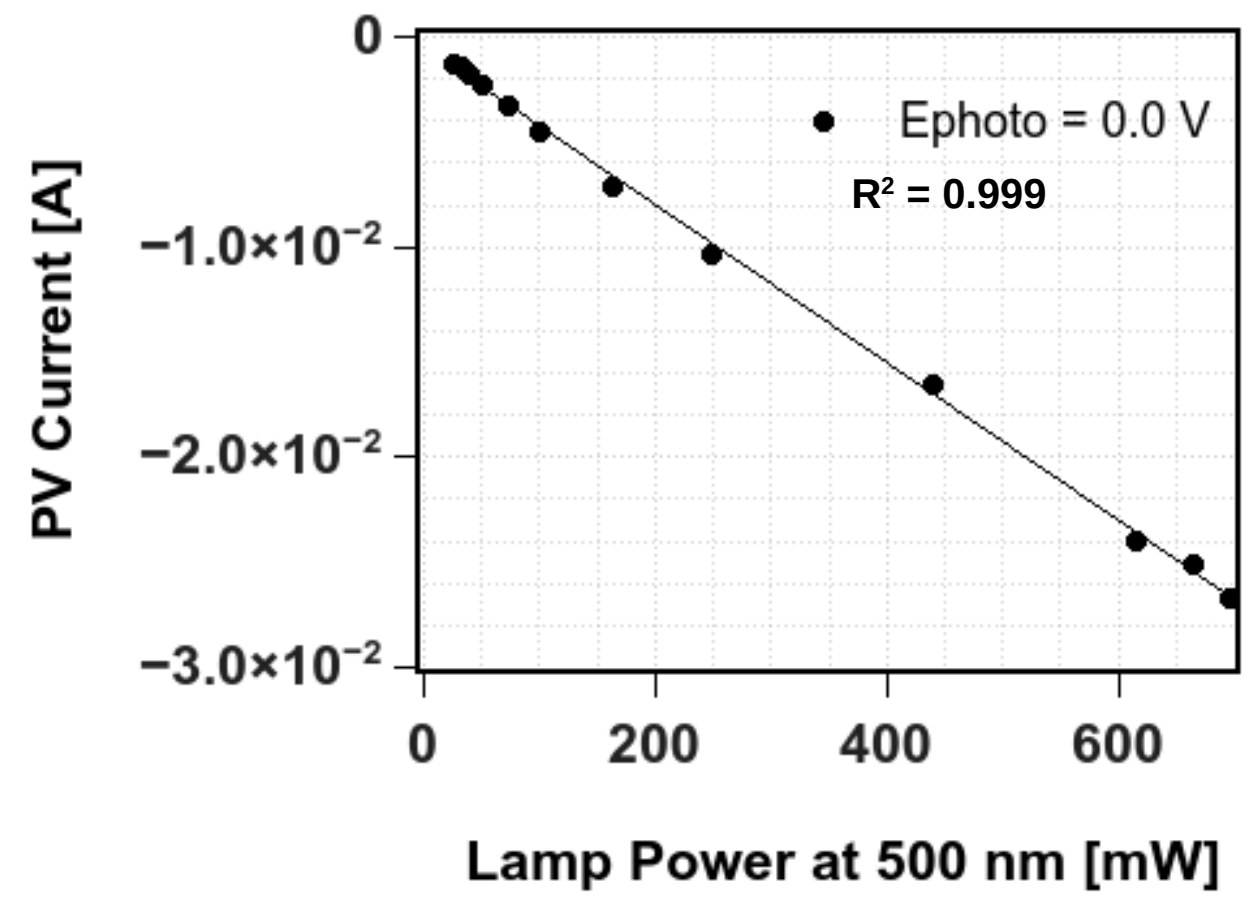

Figure S10 - Power Dependence of Photovoltaic Array

Measuring current as a function of incident light intensity over the range $0-700 \mathrm{~mW}$ demonstrates linearity of photocurrent response over conditions relevant to this study. 
Electrochemical Impedance Spectra - Figure S11

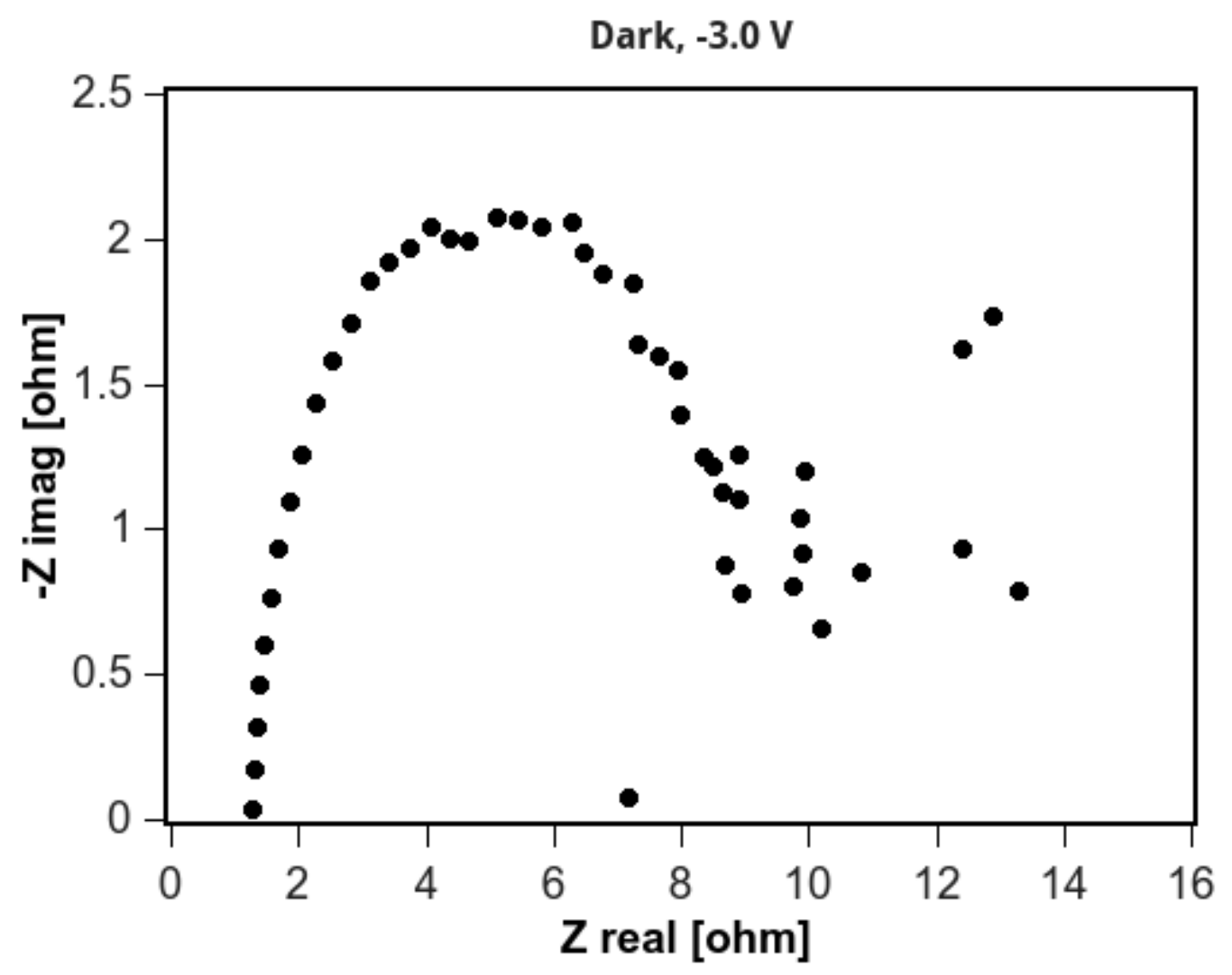


Product Distribution Dependencies: Same Voltage, Different Product Ratios

Key:

Group $1=-4.65 \mathrm{~V}$

Group $2=-3.00 \mathrm{~V}$

Group $3=-3.25 \mathrm{~V}$

Group $4=-2.75 \mathrm{~V}$

Group $5=-2.25 \mathrm{~V}$

Group $6=-2.50 \mathrm{~V}$

Group $7=-2.00 \mathrm{~V}$

Table S1: Poising the device at one voltage while changing current reals that product distribution is not simply a unique function of voltage; the same cell potential is seen to give a range of product mixtures, depending on the current.

Device Power $(\mathrm{mW})$

$\mathrm{CO} / \mathrm{H}_{2}$ Faradaic Yield ratio Cell Potential (V) Current (mA)

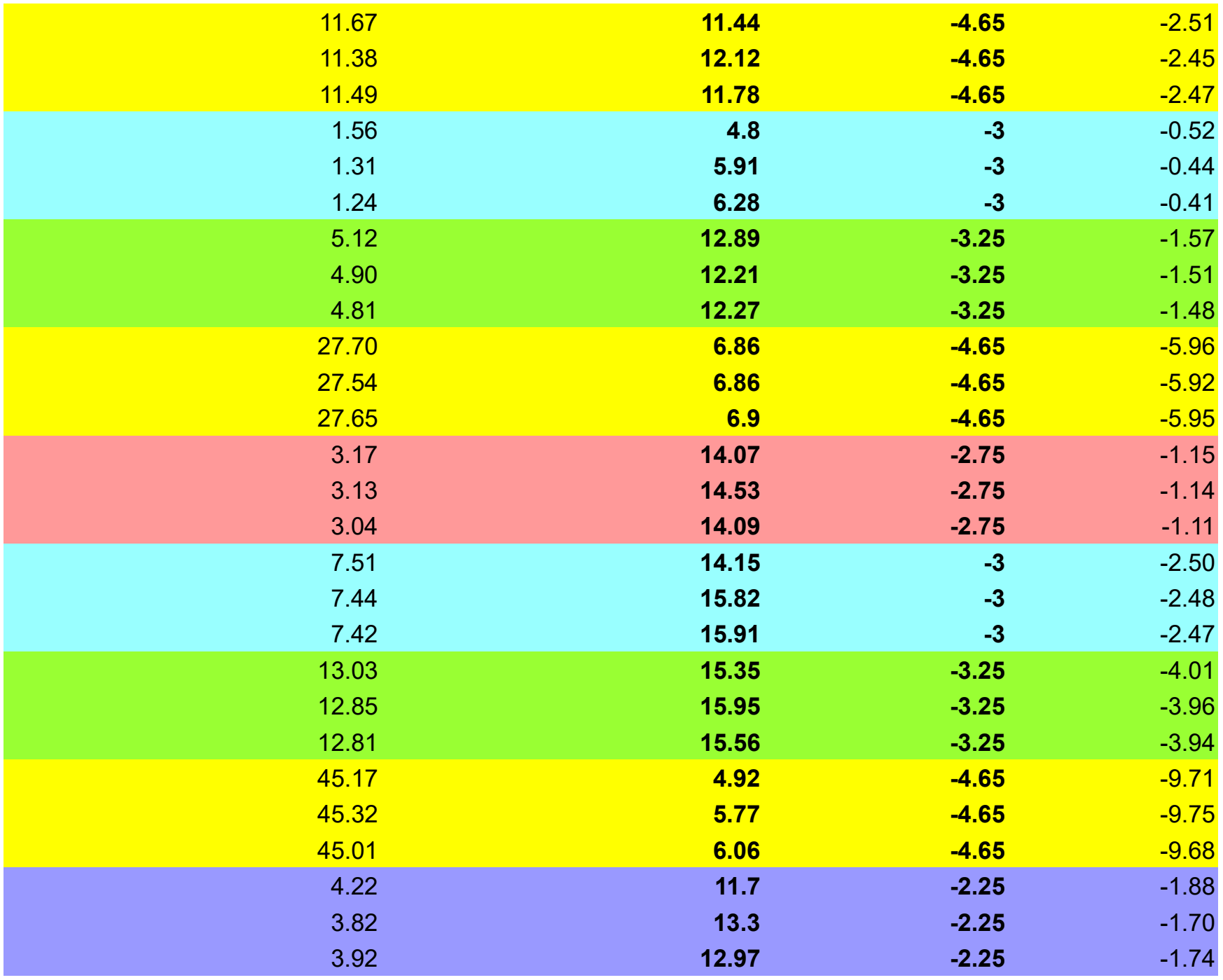


Device Power ( $\mathrm{mW})$

$\mathrm{CO} / \mathrm{H}_{2}$ Faradaic Yield ratio Cell Potential (V) Current (mA)

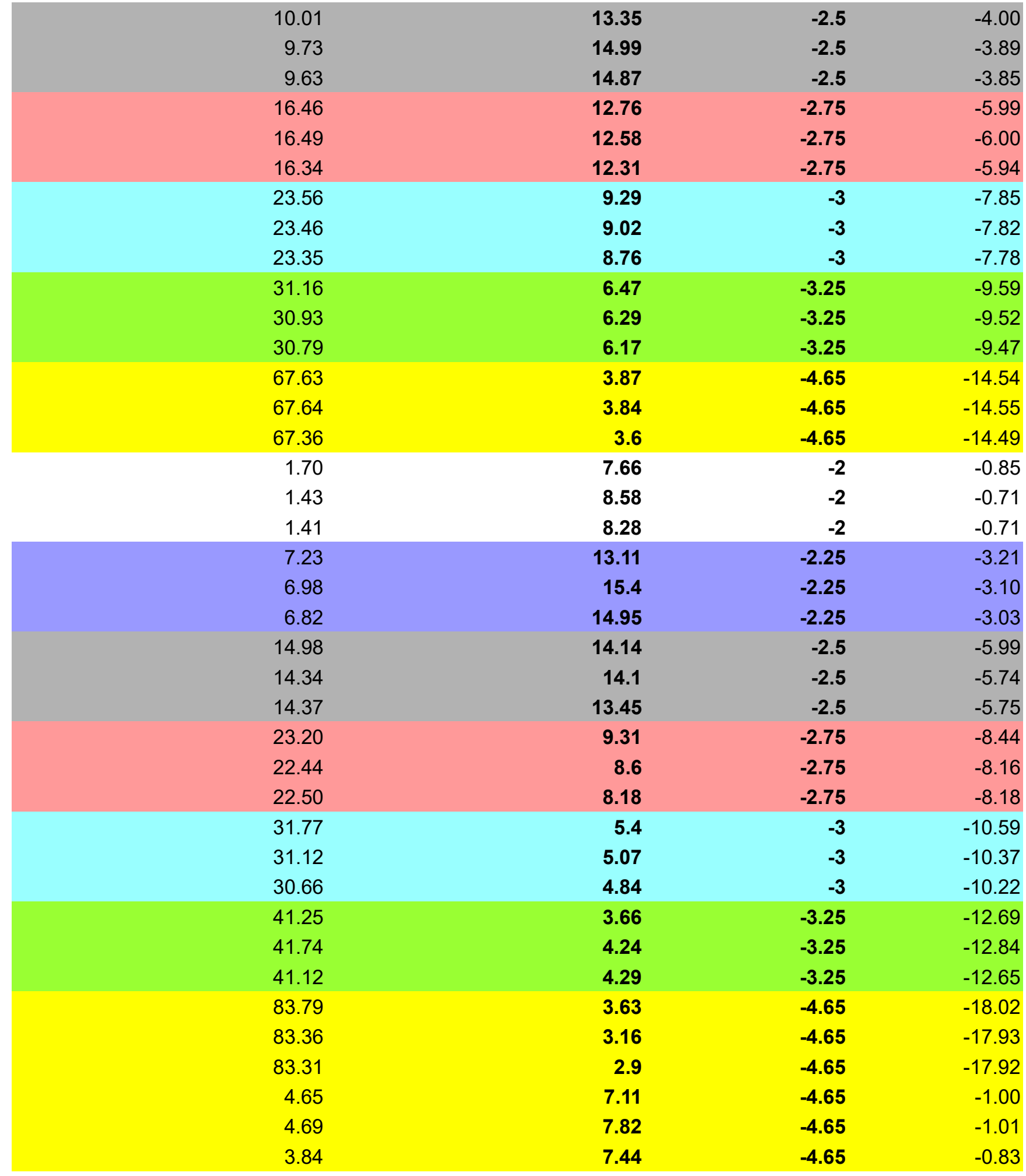


Product Distribution Dependencies: Different Voltages, Similar Product Ratios

Key:

Group 1: $\mathrm{CO} / \mathrm{H}_{2}=3$

Group 2: $\mathrm{CO} / \mathrm{H}_{2}=4-5$

Group 3: $\mathrm{CO} / \mathrm{H}_{2}=6-7$

Group 4: $\mathrm{CO} / \mathrm{H}_{2}=8-9$

Group 5: $\mathrm{CO} / \mathrm{H}_{2}=11-13$

Group 6: $\mathrm{CO} / \mathrm{H}_{2}=12-13$

Group 7: $\mathrm{CO} / \mathrm{H}_{2}=14-16$

Table S2: Similar product ratios may result even when poising the cell at very different potentials.

\section{$\mathrm{CO} / \mathrm{H}_{2}$ Faradaic Yield ratio Device Power $(\mathrm{mW})$}

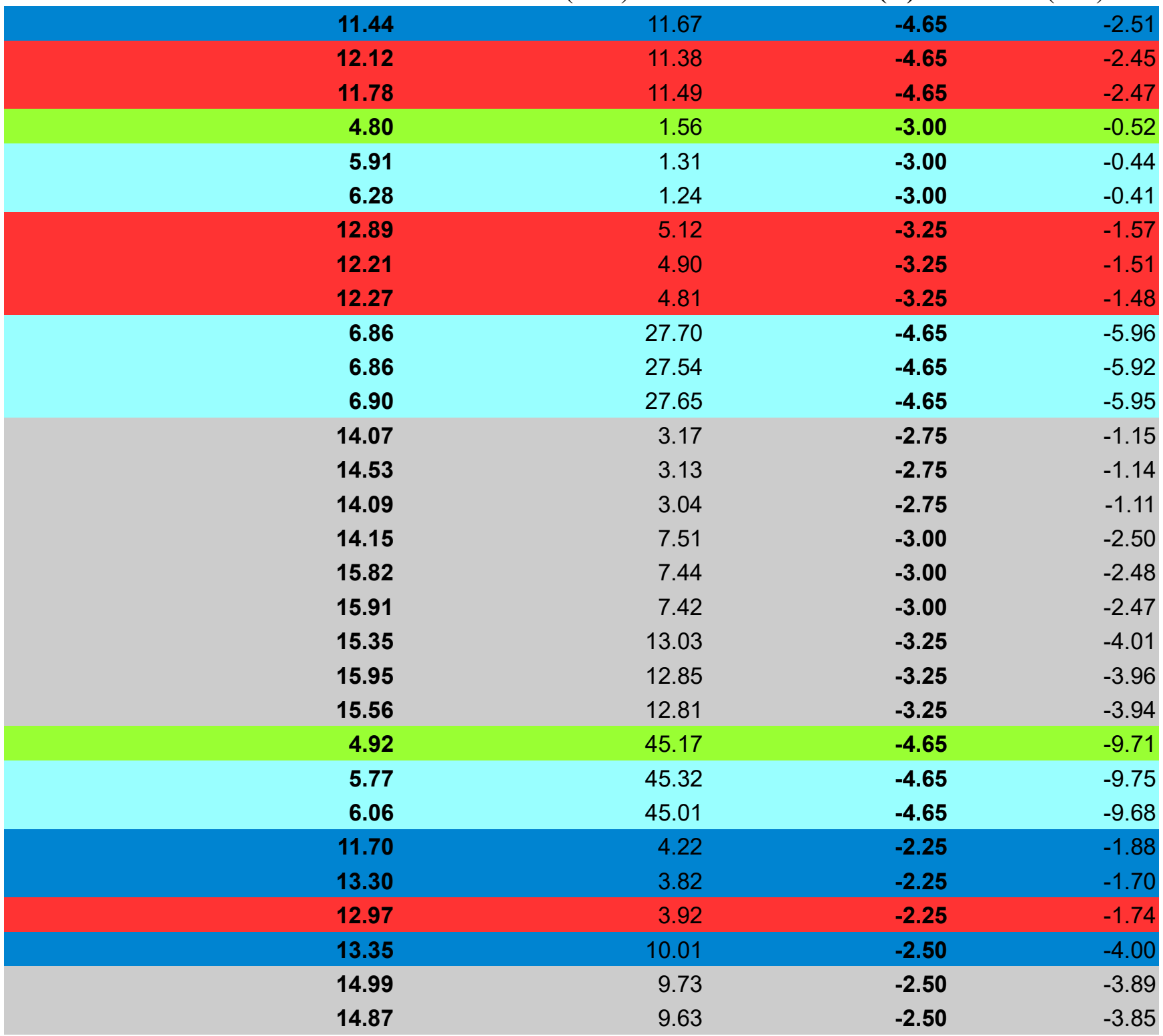




\begin{tabular}{|c|c|c|c|c|}
\hline $\mathrm{CO} / \mathrm{H}_{2}$ Faradaic Yield ratio & & & Cell Potential (V) & Current (mA) \\
\hline & 12.76 & 16.46 & -2.75 & -5.99 \\
\hline & 12.58 & 16.49 & -2.75 & -6.00 \\
\hline & 12.31 & 16.34 & -2.75 & -5.94 \\
\hline & 9.29 & 23.56 & -3.00 & -7.85 \\
\hline & 9.02 & 23.46 & -3.00 & -7.82 \\
\hline & 8.76 & 23.35 & -3.00 & -7.78 \\
\hline & 6.47 & 31.16 & -3.25 & -9.59 \\
\hline & 6.29 & 30.93 & -3.25 & -9.52 \\
\hline & 6.17 & 30.79 & -3.25 & -9.47 \\
\hline & 3.87 & 67.63 & -4.65 & -14.54 \\
\hline & 3.84 & 67.64 & -4.65 & -14.55 \\
\hline & 3.60 & 67.36 & -4.65 & -14.49 \\
\hline & 7.66 & 1.70 & -2.00 & -0.85 \\
\hline & 8.58 & 1.43 & -2.00 & -0.71 \\
\hline & 8.28 & 1.41 & -2.00 & -0.71 \\
\hline & 13.11 & 7.23 & -2.25 & -3.21 \\
\hline & 15.40 & 6.98 & -2.25 & -3.10 \\
\hline & 14.95 & 6.82 & -2.25 & -3.03 \\
\hline & 14.14 & 14.98 & -2.50 & -5.99 \\
\hline & 14.10 & 14.34 & -2.50 & -5.74 \\
\hline & 13.45 & 14.37 & -2.50 & -5.75 \\
\hline & 9.31 & 23.20 & -2.75 & -8.44 \\
\hline & 8.60 & 22.44 & -2.75 & -8.16 \\
\hline & 8.18 & 22.50 & -2.75 & -8.18 \\
\hline & 5.40 & 31.77 & -3.00 & -10.59 \\
\hline & 5.07 & 31.12 & -3.00 & -10.37 \\
\hline & 4.84 & 30.66 & -3.00 & -10.22 \\
\hline & 3.66 & 41.25 & -3.25 & -12.69 \\
\hline & 4.24 & 41.74 & -3.25 & -12.84 \\
\hline & 4.29 & 41.12 & -3.25 & -12.65 \\
\hline & 3.63 & 83.79 & -4.65 & -18.02 \\
\hline & 3.16 & 83.36 & -4.65 & -17.93 \\
\hline & 2.90 & 83.31 & -4.65 & -17.92 \\
\hline & 7.11 & 4.65 & -4.65 & -1.00 \\
\hline & 7.82 & 4.69 & -4.65 & -1.01 \\
\hline & 7.44 & 3.84 & -4.65 & -0.83 \\
\hline
\end{tabular}




\section{Approximation of $\mathrm{CO}_{2}$ Surface Concentration}

Assume ideal behavior for $\mathrm{CO}_{2}$ at $293 \mathrm{~K}$ and 1 bar, giving a concentration (C) of $2.7 \times 10^{19}$ molecules $\mathrm{CO}_{2} / \mathrm{cm}^{3}$. The resulting gas distribution is uniformly distributed about some volume, V. Calculation of the surface $\mathrm{CO}_{2}$ concentration is then approximated by considering a surface ( $\mathrm{S}$, shown in red) of dimensions $l^{2}=1 \mathrm{~cm}^{2}$ constituting the face of volume $V=l^{3}$ at $l_{x}=0$. The gas concentration at $S$, for a gas uniformly distributed in $V$, is taken as the number of $\mathrm{CO}_{2}$ molecules that can be found within some differential volume element, $d V$, integrated from $l_{x}=0$ to $l_{x}=d$. Taking $d$ as a typical molecular bond length ( $\sim 2$ A) suggests the maximum distance from $S$ at which a molecule can be considered as being located at an electrode surface. Our differential volume is therefore:

$$
l_{x} l_{y} \int_{0}^{d} d l_{z}=2 \times 10^{-8} \mathrm{~cm}^{3}
$$

with a resulting surface concentration of $\mathrm{dV} / \mathrm{V} \times \mathrm{C}=5 \times 10^{11}$ molecules $/ \mathrm{cm}^{2}$.

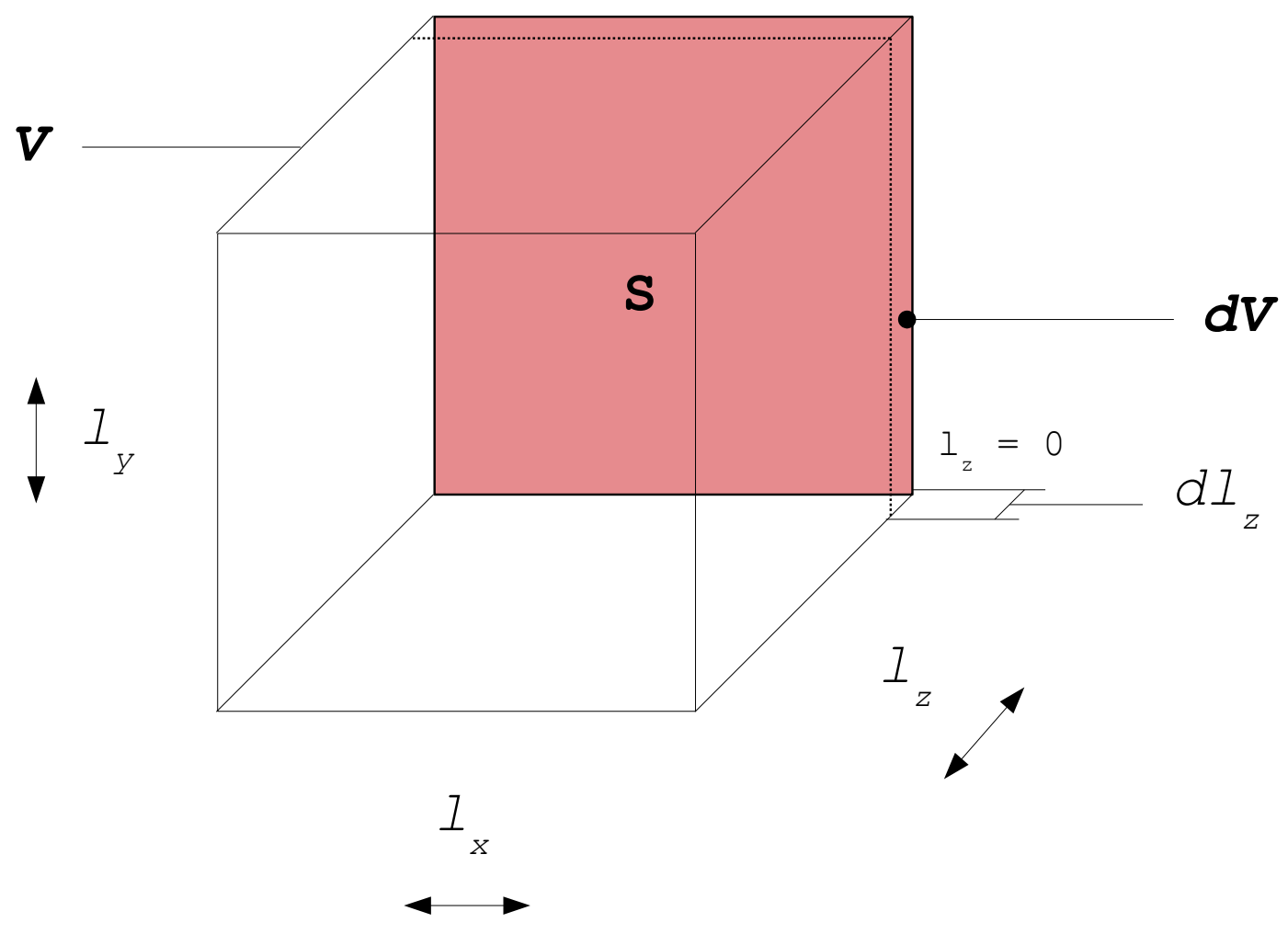




\section{Device Stability}

Steady-state current production by each device shows stable performance over the sampling period (34.5 minutes $=2070 \mathrm{~s})$. Example data shown for $560 \mathrm{~mW}$ device trials at various voltages.

Device 1:

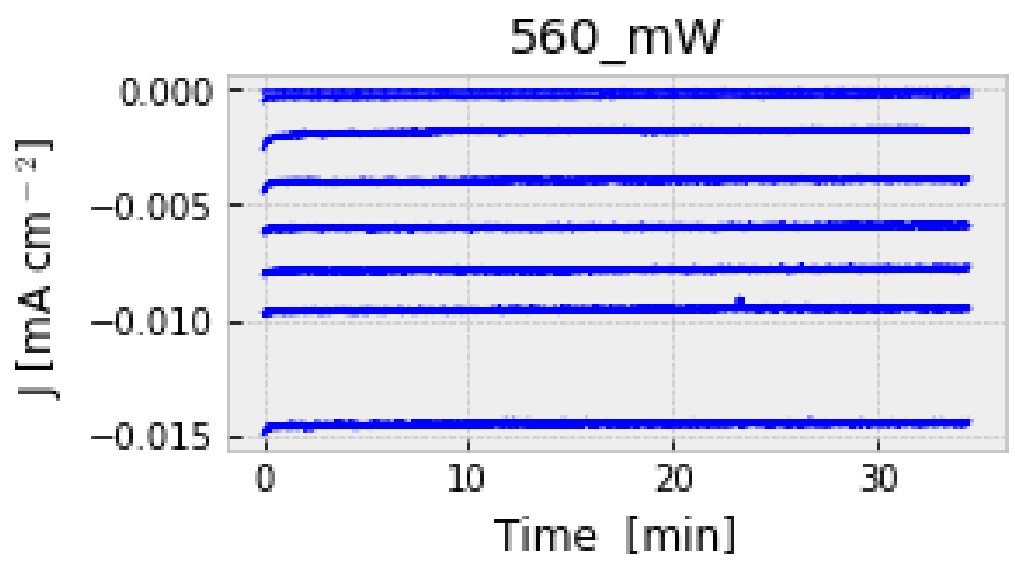

Device 2:

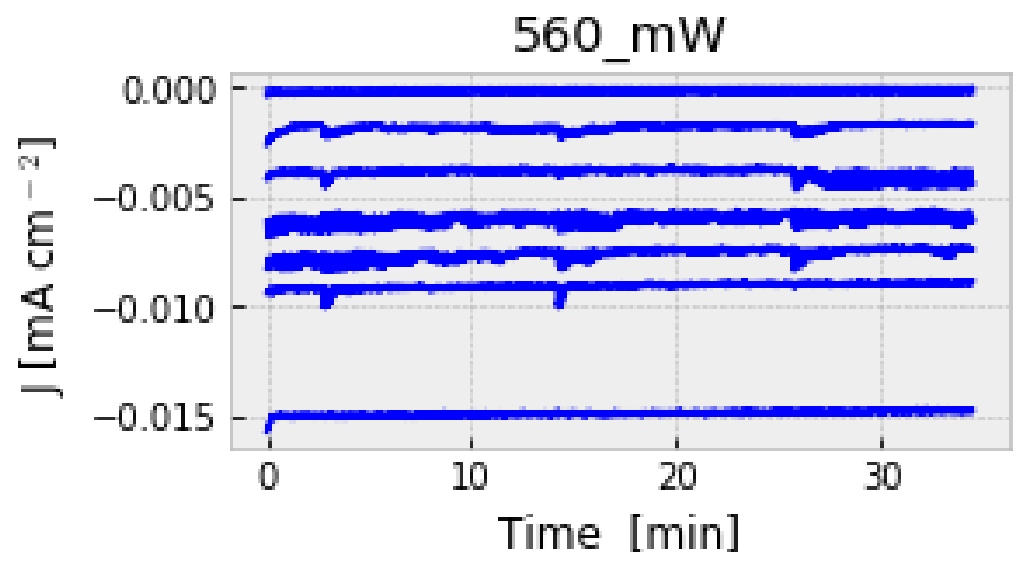

Device 3:

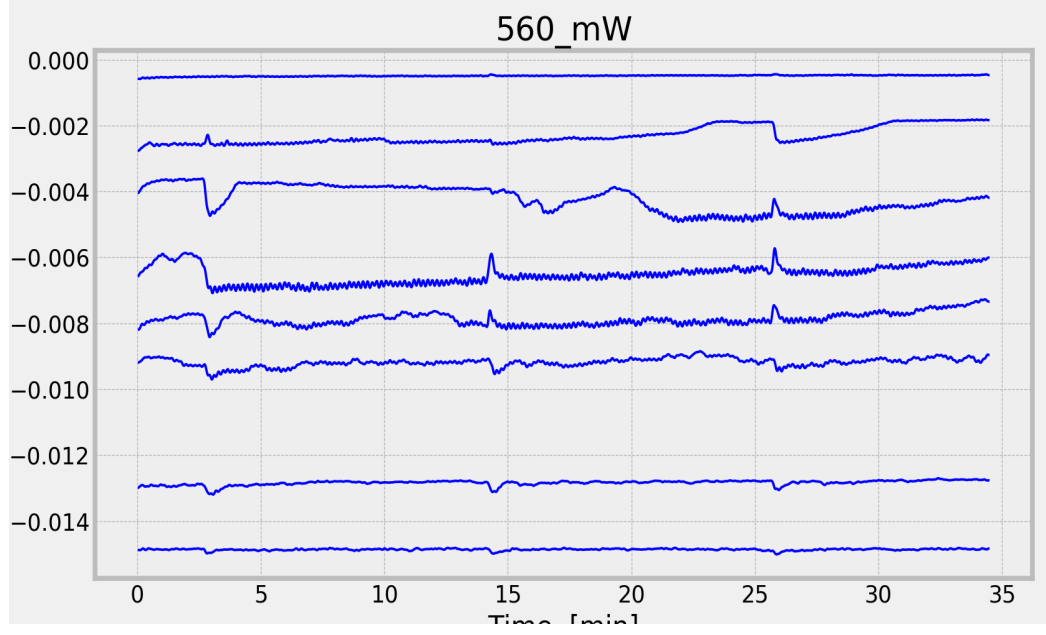

